OPEN ACCESS

Edited by:

Alfonso Abizaid,

Carleton University, Canada

Reviewed by:

Barbara Woodside,

Concordia University, Canada

Ben Nephew,

Tufts University Cummings School of Veterinary Medicine, United States

${ }^{*}$ Correspondence: Teresa Morales marter@unam.mx

Specialty section:

This article was submitted to Neuroendocrine Science, a section of the journal Frontiers in Endocrinology

Received: 13 December 2017 Accepted: 14 March 2018

Published: 28 March 2018

Citation: Muñoz-Mayorga D, Guerra-Araiza C, Torner $L$ and Morales T (2018) Tau Phosphorylation in Female

Neurodegeneration: Role of Estrogens, Progesterone, and Prolactin.

Front. Endocrinol. 9:133. doi: 10.3389/fendo.2018.00133

\section{Tau Phosphorylation in Female Neurodegeneration: Role of Estrogens, Progesterone, and Prolactin}

\author{
Daniel Muñoz-Mayorga ${ }^{1}$, Christian Guerra-Araiza ${ }^{2}$, Luz Torner $^{3}$ and Teresa Morales ${ }^{1 *}$ \\ 'Departamento de Neurobiología Celular y Molecular, Instituto de Neurobiología, Universidad Nacional Autónoma de México, \\ Querétaro, Mexico, ${ }^{2}$ Unidad de Investigación Médica en Farmacología, Hospital de Especialidades, Centro Médico Nacional \\ Siglo XXI, Instituto Mexicano del Seguro Social, Mexico City, Mexico, ${ }^{3}$ Centro de Investigación Biomédica de Michoacán, \\ Instituto Mexicano del Seguro Social, Morelia, Mexico
}

Sex differences are important to consider when studying different psychiatric, neurodevelopmental, and neurodegenerative disorders, including Alzheimer's disease (AD). These disorders can be affected by dimorphic changes in the central nervous system and be influenced by sex-specific hormones and neuroactive steroids. In fact, AD is more prevalent in women than in men. One of the main characteristics of $A D$ is the formation of neurofibrillary tangles, composed of the phosphoprotein Tau, and neuronal loss in specific brain regions. The scope of this work is to review the existing evidence on how a set of hormones (estrogen, progesterone, and prolactin) affect tau phosphorylation in the brain of females under both physiological and pathological conditions.

Keywords: tau phosphorylation, estrogen, progesterone, prolactin, hippocampus, neuroprotection, neurodegenerative disease, reproduction

\section{INTRODUCTION}

Tau protein, named after its ability to induce tubule formation (1), is a phosphoprotein that is almost exclusively found in neurons, and it has six molecular isoforms derived from the alternative splicing of a single gene (2). Tau is mostly found in the axon $(3,4)$, but its presence has also been reported in dendrites, oligodendrocytes, and astrocytes (5-7).

The relevance of tau in a number of neurodegenerative diseases, especially Alzheimer's disease (AD), has been widely documented (8). When in hyperphosphorylated state ( $\mathrm{p}$-Tau), tau aggregates to form neurofibrillary tangles (NFTs), a hallmark of AD (9). Currently, the triggers and threshold for tau to change into an aggregated pathogenic promotor are not well understood (10). Since only a small percentage of $\mathrm{AD}$ cases have a genetic background, research has led to the identification of risk factors, among the most studied are: age (the greatest risk factor), proneness to experience stress $(11,12)$, anxiety and depression (13), head injury, lack of physical exercise, obesity (14), low education level (15), and sex (16).

Sex differences are present across several psychiatric, neurodevelopmental, and neurodegenerative disorders, including $\mathrm{AD}(17,18)$. Moreover, females undergo hormonal changes throughout life, which affect p-Tau (19). Among these changes, reproductive conditions such as puberty, the use of hormonal contraceptive methods, length of reproductive life, and pregnancy at late age have shown to correlate with better cognitive performance in postmenopausal stage (20). More importantly, breastfeeding is related to a reduced risk to develop $\mathrm{AD}$, especially when performed for 
a prolonged period (21). Likewise, maternal experience results in better performance in hippocampus-dependent learning tasks (22) and acute stress during lactation induces a decrease in hippocampal p-Tau compared to unstressed controls in rats (23). The following sections will focus on the role of a specific set of hormones (i.e., estrogen, progesterone, and prolactin) and its consequences for $\mathrm{p}$-Tau.

\section{REGULATION OF TAU PHOSPHORYLATION}

Tau phosphorylation is not only relevant to $\mathrm{AD}$, but it is also a process that occurs in physiological conditions. The most emblematic function of tau is the ability to bind and stabilize microtubules by copolymerization with tubulin. This function is tightly regulated by the phosphorylation state of tau: when in a more dephosphorylated state, tau is more efficient at promoting microtubule formation (24). As a consequence of this hallmark function, tau also participates in axogenesis, axonal transport, neurite extension processes $(25,26)$, and coordinated phosphorylation and dephosphorylation within the microtubule has been proposed as a step for neurite outgrowth (27).

Tau phosphorylation is a dynamic process that relies on the interaction of different kinases (enzymes adding phosphate groups to serine, $\mathrm{S}$; threonine, $\mathrm{T}$; and tyrosine, $\mathrm{Y}$ ) and phosphatases (enzymes removing phosphate groups from $\mathrm{S}, \mathrm{T}$, and $\mathrm{Y}$ ) (28). In spite of the large number of kinases that phosphorylate tau protein, just a few have been implicated as prominent players in abnormal tau processing in vivo, such as glycogen synthase kinase $3 \beta$ (GSK3 $\beta$ ) and cdk-5 (29). Regarding phosphatases, tau can be dephosphorylated by PP1, PP2A, PP2B, and PP5 (28-30). Phosphatase activity in normal brains is due to PP2A in $71 \%$ and PP2B in $11 \%$ of the cases, making PP2A a major brain and tau phosphatase (30). In $\mathrm{AD}$, the activity of PP2A is reduced by half and that causes tau hyperphosphorylation and memory deficits, while increasing GSK3 $\beta$ activity (28).

The most studied tau kinases in the field of AD are GSK3, cdk5, mitogen-activated protein kinase (MAPK) (p38, ERK1/2, JNK), CK1, and MARK. GSK3 is able to phosphorylate 42 sites of tau, 29 of which are found in brains with AD (31). GSK3 refers to two homologous proteins that are paralogs: GSK3 $\alpha$ and GSK3 $\beta$. The catalytic sites of both are identical except for a glycine-rich $\mathrm{N}$-terminal region in the GSK3 $\alpha$, which is absent in the GSK3 $\beta$ paralog. The mechanisms regulating their expression are not well understood and some differential actions in synaptic plasticity and disease are known. More research is needed to clarify the role of each paralog in different physiological and pathological pathways (Figure 1) [see Ref. (32) for review].

P-tau has been implicated in neuronal plasticity. For example, its most phosphorylated isoform is expressed in fetal stages (2), reversible and transient hyperphosphorylation occurs during hibernation and deep anesthesia in squirrels (33), and pregnancy and lactation alter tau expression and p-Tau in rats (34). Regarding $\mathrm{AD}$, cognitive and memory impairment have been correlated with synapse loss in the prefrontal cortex (35) and in other brain areas (36) of AD patients, along with presence of tau NFTs (37).
Immunization of 3xTg-AD mice against the $\mathrm{N}$-terminal domain of tau decreased p-Tau and reduced the cognitive deficits in reference memory, as observed in the Morris water maze (38).

Studies using GSK3 $\beta$ show that hippocampal degeneration is mediated by $\mathrm{p}$-Tau, which presents colocalization with the aforementioned NFTs. Besides, the increased GSK3 $\beta$ activity by $\mathrm{AB}$ peptides also causes tau hyperphosphorylation in the hippocampus of rodents (31), while inhibition of GSK3 $\beta$ can protect neurons from $\mathrm{AB}$ toxicity. Moreover, once $\mathrm{cdk} 5$ phosphorylates tau, it primes the protein to be more efficiently phosphorylated by GSK3 $\beta$ (31) showing that interactions among enzymes that regulate $\mathrm{p}$-tau should be taken into account (Figure 1).

\section{HORMONE ACTIONS AND THEIR RELATION TO NEURODEGENERATIVE DISEASES AND TAU PHOSPHORYLATION}

Epidemiological studies show a significantly higher prevalence of $\mathrm{AD}$ in women than in men, which is usually explained by the longer lifespan of women (39). A considerable amount of research shows that the higher frequency in women may be due to the interplay between age and sex, in which, factors such as genetics, metabolic changes, and hormones play a prominent role (40). Ovarian hormones, such as estrogens and progesterone, could interact with other risk factors (obesity, neuroinflammation, mitochondrial dysfunction, etc.) to develop $\operatorname{AD}(15,41)$.

The notion of female sex as a risk factor for $\operatorname{AD}(16,40)$ is also supported by studies using transgenic mouse models of $\mathrm{AD}$ where sex differences were documented, suggesting that females are more vulnerable to the neuropathology (16). In addition, the hippocampal response to stress shows that females are more vulnerable to tau (42) and $\mathrm{AB}$ pathology (43) than males.

In line with this, menopause, characterized by the loss of estrogens and progesterone due to aging, is strongly associated with a higher vulnerability to develop $\mathrm{AD}$ (16). The absence of ovarian hormones increases the age-induced $\mathrm{p}$-Tau in the hippocampus of rats (44). Regarding estrogens, plasma levels of $17 \beta$-estradiol are lower in women with $\mathrm{AD}$ compared with age-matched controls and some estrogen-based approaches to reduce $\mathrm{AD}$ risk have been designed, although with contradictory results (19). Progesterone, also depleted in menopause, has known effects in AD neuropathology (45). Progesterone and its metabolites can exert neuroprotective actions by themselves $(19,46)$, although it can potentiate or block the protective effects of estrogens. In rats treated with estrogens, progesterone blocked estrogen-induced spatial memory improvement and neuroprotection from excitotoxic injury, among others. Such antagonistic mechanisms are not yet fully understood (19).

On the other hand, there is a strong correlation between reproductive history and cognition in postmenopausal women. Particularly, women who had their last pregnancy later in life showed better verbal and global cognitive performance (18). Furthermore, mothers outperform nulliparous rats in learning and memory tasks (47), and these positive changes may endure into senescence (19). During their lifetime, most females undergo radical physiological changes induced by the maternal experience (47). 


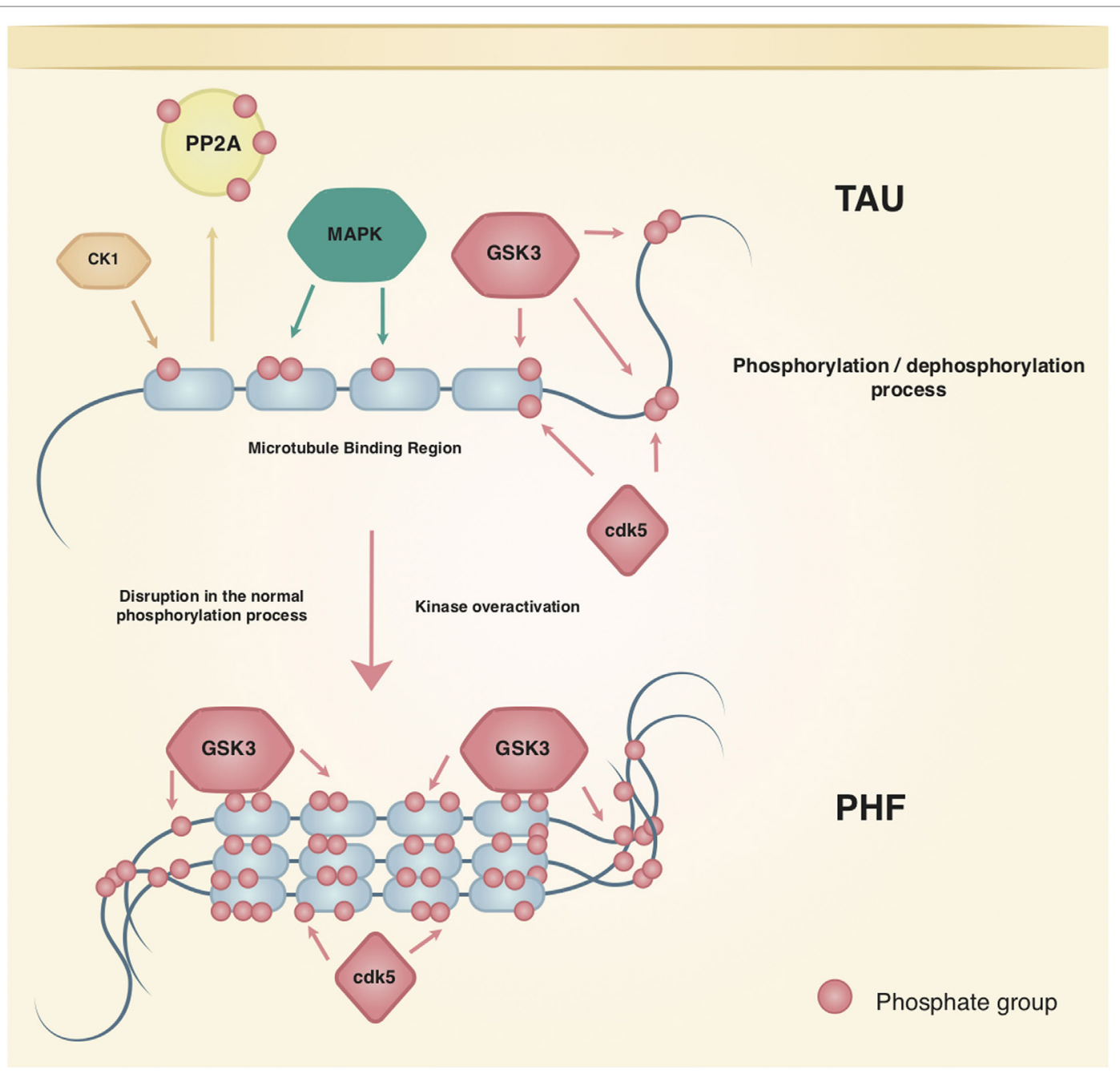

FIGURE 1 | Regulation of tau phosphorylation. Tau is a native phosphoprotein that relies on an equilibrium of phosphorylation and dephosphorylation to perform physiological and neuroplasticity processes. Tau most studied kinases and phosphatase are shown; kinases such as cdk5 and GSK3 have been related to the hallmark lesions in Alzheimer's disease.

Hormones such as prolactin, oxytocin, and endorphins produce these changes, which fundamentally alter the functions of the HPA axis (48).

For such changes in the female brain to occur during the reproductive experience, a great deal of plasticity is required (47). This plasticity translates into changes in the cytoskeleton and microtubule-associated proteins, for example, Tau content in the hippocampus decreases throughout pregnancy, but the ratio of phosphorylated tau increases in pregnancy and lactation $(24,46)$. Estrogen, progesterone, the interplay between them, and other hormones $(49,50)$ are known to be involved in those changes.

\section{Estrogens}

Estrogens have long been known to exert neuroprotective effects in different models of central nervous system diseases such as AD, Parkinson's disease, and multiple sclerosis (51). Estrogens may exert their neuroprotective properties through estrogen receptor $\alpha(E R-\alpha)$, which is known to interact with insulin-like growth factor 1 receptor (IGF-1R), by incorporating itself into a macromolecular complex with the components of IGF-1R signaling (49). These include phosphoinositol 3 kinase (PI3K), protein kinase B (Akt), GSK3 $\beta$, and $\beta$-catenin. The activation of PI3K and Akt results in inhibition of GSK3 $\beta$ (by phosphorylation of the site Ser9), therefore, reducing p-Tau $(52,53)$ (Figure 2).

In the hippocampus of ovariectomized rats sacrificed $1 \mathrm{~h}$ after treatment with estradiol, GSK3 phosphorylation increases significantly in $\mathrm{Ser}^{9 / 21}$, a site that inactivates GSK3. In addition, there is less phosphorylation in the PHF-1 epitope, which recognizes phosphorylation in Ser ${ }^{396 / 404}$, a site observed in $\mathrm{AD}$ brains, both in vivo and in vitro. It was also observed that $\beta$-catenin, a key protein regulated by GSK-3 and located in the Wnt/wingless pathway, co-immunoprecipitated with ER $\alpha$. These results support the idea that a multi-complex between ER- $\alpha, \beta$-catenin, and GSK 3 is formed to modulate the activity of GSK3, and in turn, tau phosphorylation, through the Wnt and Akt pathways $(52,54)$. 


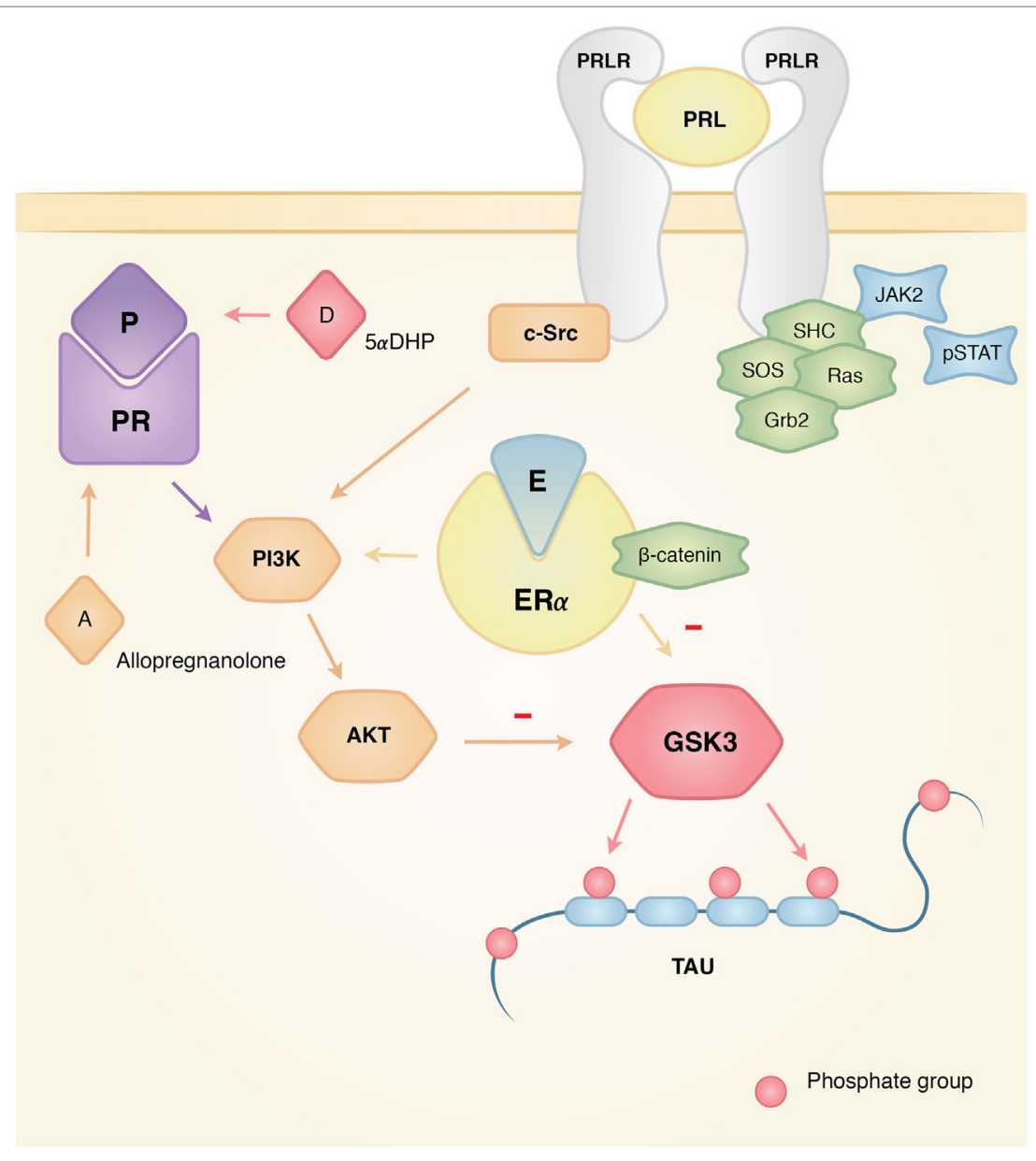

FIGURE 2 | Actions of estrogen, progesterone, and prolactin on tau phosphorylation. Interacting mechanisms of hormone action that affect the dynamics of tau phosphorylation. The three hormones have documented activity in the activation of Akt that makes GSK3 inactive, which results in the inhibition of tau phosphorylation for this particular kinase. Since GSK3 has been linked in the pathological development of Alzheimer's disease (AD), the interplay between these hormones, their pathways, and GSK3 might explain why the absence of hormones could account for the higher risk of developing AD. On the other hand, the presence of hormones like prolactin might prove neuroprotective for the neurodegeneration of the female brain.

In N2a cell cultures (neuroblastoma cell line) treated with Wortmannin and GF-109203X to induce GSK3 $\beta$ activation and $\mathrm{p}$-Tau, the treatment with $17 \beta$-estradiol resulted in attenuated $\mathrm{p}$-Tau at sites $\mathrm{Ser}^{396 / 404}, \mathrm{Thr}^{231}, \mathrm{Thr}^{205}$, and $\mathrm{Ser}^{199 / 202}$ (55). Furthermore, when a transient deactivation of Akt (the upstream regulator of GSK3 $\beta$ ) was induced, $17 \beta$-estradiol increased the levels of GSK3 $\beta$ phosphorylated in Ser ${ }^{9}$, which suggests that estrogens can also target GSK3 $\beta$ directly and affect tau phosphorylation without the upstream effector Akt, in addition to the pathway described above (55).

In vitro studies in human neuroblastoma and primary rat cortical neuron showed that treatment with estradiol increased tau dephosphorylation as assessed with Tau-1 antibody, which recognizes a proline-directed non-phosphorylated site of tau (56). Moreover, when tau hyperphosphorylation was induced by okadaic acid in differentiated human neuroblastoma cells, treatment with estradiol for $24 \mathrm{~h}$ decreased p-Tau measured by 12E8 tau antibody (which recognizes phosphorylation in $\mathrm{Se}^{262}$ within the microtubule-binding region and is not a proline-directed site)
(56). Estrogen treatment also affected p-Tau in both undifferentiated and differentiated neuroblastoma cells (56). According to this study, the ER receptor seems to be involved in these effects, likely via the Akt pathway [see above, Ref. $(52,53)]$.

On the other hand, when using in vivo models of $\mathrm{AD}$, the neuroprotective actions of estrogens are mainly related to $A B$ production and clearance [see Ref. (45) for review]. Nevertheless, in a study using $3 \times \mathrm{Tg}-\mathrm{AD}$ transgenic female mice that develop the complete $\mathrm{AD}$ neuropathology, the ovariectomized group that was treated with estrogens and progesterone showed a robust decrease in AT8 immunoreactivity, which detects tau phosphorylated at sites Ser/Thr ${ }^{202 / 205}$, in hippocampal neurons. This result shows that the combination of the hormones can regulate $\mathrm{AD}$ neuropathology and their absence could be deleterious (57).

Finally, when ovariectomized female rats were chronically treated with estrogen, progesterone, and tibolone (TIB) (a widely prescribed synthetic steroid with estrogenic, progestogenic, and androgenic actions), less p-Tau in the epitope PHF-1 and more dephosphorylation in the antibody Tau-1 was detected, in both 
the hippocampus and the cerebellum (58). In this particular study, no changes were detected in GSK $3 \beta \operatorname{Ser}^{9}$ in the hippocampus, in contrast to the findings in the cerebellum, suggesting the involvement of different pathways or a region-specific action for this enzyme.

\section{Progesterone}

Like estrogens, progesterone is a hormone that is mainly synthesized in the ovary and exerts neuroprotective effects in several models of disease such as $\mathrm{AD}$, stroke, and traumatic brain injury (59, 60). Progesterone can elicit its neuroprotective effects through progesterone receptors (PR) A and B. Interestingly, PR-A can also modulate the activity of PR-B, ER (which might explain its antagonistic or synergistic effects when administered with estradiol) and the glucocorticoid receptor. It has also been shown that progesterone can activate signal transduction pathways such as cAMP/PKA, MAPK (ERK1/2), and PI-3K/Akt (60) (Figure 2).

In relation to tau, progesterone, and its metabolites, DHP (5-alpha-dihydroprogesterone) and THP (3-alpha, 5-alphatetrahydroprogesterone, also known as allopregnanolone) have been shown to significantly reduce tau protein expression in the rat cerebellum (46). Moreover, progesterone induces tau phosphorylation in the epitope Tau-1 and PHF-1 (sites Ser ${ }^{396 / 404}$ ) in the same structure, but this effect is not present when DHP or THP are administered. Since the epitope Ser262 (not phosphorylated by GSK3) was unaffected by progesterone treatment, while the epitope PHF-1 (phosphorylated by GSK3) responded to the same treatment, this implies that GSK3 is a possible candidate for the described progesterone effects (46).

Also, in the study by Carroll (57) mentioned earlier, p-Tau decreased significantly when ovariectomized female 3xTg mice were treated with progesterone and a progesterone/estrogens cocktail, as observed by immunoreactivity to the AT8 antibody in CA1 and subiculum subfields of the hippocampus. Based on these results, the authors suggest that the observed effect could be due to the regulation of GSK3 $\beta$ by progesterone (46).

On the other hand, treatment with physiological levels of progesterone $24 \mathrm{~h}$ prior to sacrifice increased the expression of the catalytic and regulatory subunits of PI3K and the phosphorylation of Akt in the hypothalamus, hippocampus, and cerebellum of ovariectomized rats. This effect was partially mimicked by progesterone-reduced metabolites DHP and allopregnanolone in the hypothalamus and hippocampus, but not in the cerebellum (61). This study provides a likely pathway for the decrease in $\mathrm{p}$-Tau by Akt phosphorylation, upstream to the inactivation of GSK3 $\beta$ in both cerebellum (46) and hippocampus (57). Also, progesterone increases the levels of the phosphatase PP2A phosphorylated in $\mathrm{Y}^{307}$, which inactivates this enzyme, in hippocampus and cerebellum (62).

It is worth noting that when estradiol was given prior to progesterone, an increase in $\mathrm{Y}^{307}$ phosphorylation was seen only in the cerebellum, which suggests that the regulation of PP2A by progesterone is region specific (62) and that a complex interplay between estrogens and progesterone regulates kinases and phosphatases $(61,62)$. Furthermore, exposure to either continuous or cyclic treatment of progesterone induced significantly less AT8 immunoreactive neurons in the $3 \mathrm{xTg}-\mathrm{AD}$ model compared to their respective controls (63).

In ovariectomized female rats exposed to a 60-day treatment of estrogens, progesterone, or TIB, all compounds resulted in a significant decrease of $\mathrm{p}$-Tau in the PHF-1 epitope and in higher levels of dephosphorylated tau in the hippocampus, as measured with Tau-1 antibody. However, progesterone had no effect in the cerebellum, and no differences in $\mathrm{Ser}^{9}$ phosphorylation were seen in GSK3 $\beta$ (58). Previous studies have shown reduced phosphorylation in the cerebellum coupled with changes in GSK3 $\beta$ activity after an acute treatment with progesterone (46). However, the chronic administration of progesterone that results in less phosphorylation could be mediated by other kinase mechanisms, such as ERK or cdk5, or by the involvement of phosphatases such as $\mathrm{PP} 2 \mathrm{~A}(58,62)$.

A recent study using low and high doses of TIB showed decreased $\mathrm{p}$-Tau in the PHF-1 epitope in the hippocampus of male aged rats through the regulation of PI3K/Akt and cdk5/ p35/p25 pathways (64). Whether these pathways also mediate the action of TIB in the hippocampus of females is unknown. It is important to mention that both allopregnanolone and TIB have been proposed as neuroprotective agents, and that allopregnanolone is currently considered as a candidate therapeutic agent in patients with $\mathrm{AD}$ and postpartum depression, another risk factor of $\mathrm{AD}(13,65-67)$.

\section{Prolactin}

Prolactin is a pituitary hormone that is primarily involved in milk synthesis and maternal behavior (68). Beyond these wellknown functions, it has been shown that prolactin provides neuroprotection to the hippocampus in the kainic model of epilepsy $(69,70)$ and attenuates the neuroendocrine responses to stress $(71,72)$. There is evidence that breastfeeding lowers the risk to develop $\mathrm{AD}$ in humans (21), and tau expression undergoes changes during pregnancy along with an increase in P-Tau in several brain areas of rats throughout pregnancy until day 2 of lactation (27). These data point to the maternal experience as a regulator of tau phosphorylation, being prolactin a likely candidate for promoting these changes due to its elevated concentration during lactation and its actions inhibiting the HPA axis (72). We found that exposure to one episode of restraint stress significantly reduced $\mathrm{p}$-Tau in the hippocampus of lactating dams compared to virgin or postweaned rats. This decrease was coupled with reduced detection of GSK3 $\alpha$ (23).

Given that lactation is considered a hyperprolactinemic state, it is possible that the elevated levels of prolactin affect signaling pathways related to kinases that regulate $\mathrm{p}$-Tau (Figure 2). Previous studies using male mice subjected to the same stress protocol showed increased p-Tau insolubility in the hippocampus (73), which reinforces the view that prolactin could regulate aspects of tau phosphorylation in the hippocampus.

Prolactin exerts its effects through prolactin receptors (PRL-R) via long, intermediate, and short isoforms encoded by a single gene. After homodimerization of the PRL-R, long-long homodimers can activate second messenger pathways, particularly the JAK-signal transducer and activator of transcription signaling 
cascade. Short-short homodimers activate the MAPK pathway and, finally, long and short heterodimers are known to block PRL-R signaling and modulate its effects (74).

Although a direct link between prolactin and $\mathrm{p}$-Tau has not been investigated, evidence from prolactin pathways involving GSK3 $\beta$ suggests that the hormone influences p-Tau. In W53 lymphoid cells, prolactin increases the activity of the Akt pathway, thereby phosphorylating GSK3 $\beta$ in Ser9 causing its deactivation (75). On the other hand, a study using breast cancer cell lines identified GSK3 $\beta$ as a kinase of the prolactin receptor at Ser349; this phosphorylation site labels the prolactin receptor for degradation (76).

\section{FUTURE PERSPECTIVES}

The fact that diverse results in the AD field have surfaced between males and females at different ages, reproductive stages, and in response to different stimuli points toward a new direction in sex-related $\mathrm{AD}$ research $(23,45,77)$ (Table 1). Thus, detailed attention must be given to the study of aging, different reproductive stages and hormones involved, and the interplay with other risk factors in females $(21,77)$.

A considerable amount of studies shows that estrogens and progesterone play an important role in regulating $\mathrm{p}$-Tau in different conditions. However, the evidence about prolactin influencing p-Tau is still missing despite the importance of this hormone in reproductive life. Moreover, it is important to have thorough knowledge of how puberty, the estrous cycle, pregnancy, lactation, and maternal experience affect $\mathrm{p}$-Tau, since all of these life events are characterized by hormonal fluctuations that cause fundamental changes in the female's brain.

Also, it is extremely important to acknowledge that inflammation plays a critical role in the development of $\mathrm{AD}$, through interactions with risk factors, such as obesity and depression, and with the hormones described above (13, 15, 41, 78). Further research needs to address inflammation in relation to other risk factors and markers of the disease $(12,15,23)$

\section{REFERENCES}

1. Weingarten MD, Lockwood AH, Hwo SY, Kirschner MW. A protein factor essential for microtubule assembly. Proc Natl Acad Sci U S A (1975) 72(5):1858-62. doi:10.1073/pnas.72.5.1858

2. Kolarova M, García-Sierra F, Bartos A, Ricny J, Ripova D. Structure and pathology of tau protein in Alzheimer disease. Int J Alzheimers Dis (2012) 2012:731526. doi:10.1155/2012/731526

3. Binder L, Frankfurter A, Rebhuhn L. The distribution of tau in the mammalian central nervous system. J Cell Biol (1985) 101:1371-8. doi:10.1083/ jcb.101.4.1371

4. Trojanowsky JQ, Schuck T, Schmidt ML, Lee VM-Y. Distribution of tau proteins in the normal human central and peripheral nervous system. J Histochem Cytochem (1989) 37(2):209-15. doi:10.1177/37.2.2492045

5. Kosik KS, Finch EA. MAP2 and tau segregate into dendritic and axonal domains after the elaboration of morphologically distinct neurites: an immunocytochemical study of cultured rat cerebrum. J Neurosci (1987) 7(10): 3142-53.

6. Ittner LM, Götz J. Amyloid- $\beta$ and tau - a toxic pas de deux in Alzheimer's disease. Nat Rev Neurosci (2010) 12:2. doi:10.1038/nrn2967

7. Kahlson MA, Colodner KJ. Glial tau pathology in tauopathies: functional consequences. J Exp Neurosci (2016) 9(S2):43-50. doi:10.4137/JEN.S25515
TABLE 1 | Phosphorylation sites in tau influenced by estrogen, progesterone, and prolactin.

\begin{tabular}{llc}
\hline Hormone & Phosphorylation site & Reference \\
\hline Estrogens & Ser396/404 & $(54-57)$ \\
& Ser262 & \\
& Ser202/Thr205 & \\
& Thr231, Thr205, Ser199/202 & \\
Progesterone & Ser396/404 & $(46,57,63)$ \\
Ser202/Thr205 & \\
Prolactin* & Ser396/404, Ser202/Thr205* & Steinmetz et al.* (23)
\end{tabular}

*It must be noted that the evidence about prolactin influencing these phosphorylation sites is not direct and needs more research.

to elucidate why females appear to be protected from injury and neurodegeneration during lactation and more vulnerable during menopause.

\section{AUTHOR CONTRIBUTIONS}

DM-M, CG-A, LT, and TM wrote and edited the review article. $\mathrm{DM}-\mathrm{M}$ and $\mathrm{TM}$ created the figures.

\section{ACKNOWLEDGMENTS}

The authors thank Jessica González Norris and Ilektra Anagnostou for editing the English version of this manuscript, and Fernanda Muñoz-Niembro for graphic design.

\section{FUNDING}

Cited research supported by UNAM-DGAPA-PAPIIT to TM (IN202315, IN204718). DM-M is a graduate student of the Programa de Doctorado en Ciencias Biomédicas UNAM, supported by CONACyT scholarship (CVU/Recipient: 662482/ 574065). CG-A received Scholarship of Excellence in Research by Fundación IMSS.

8. Buée L, Bussière T, Buée-Scherrer V, Delacourte A, Hof PR. Tau protein isoforms, phosphorylation and role in neurodegenerative disorders. Brain Res Brain Res Rev (2002) 33(1):95-130. doi:10.1016/S0165-0173(00)00019-9

9. Alonso A, Zaidi T, Novak M, Grundke-Iqbal I, Iqbal K. Hyperphosphorylation induces self-assembly of into tangles of paired helical filaments straight filaments. Proc Natl Acad Sci U S A (2001) 98(12):6923-8. doi:10.1073/pnas.121119298

10. Crespo-Biel N, Theunis C, Van Leuven F. Protein tau: prime cause of synaptic and neuronal degeneration in Alzheimer's disease. Int J Alzheimers Dis (2012) 2012:251426. doi:10.1155/2012/251426

11. Rissman RA. Stress-induced tau phosphorylation: functional neuroplasticity or neuronal vulnerability? J Alzheimers Dis (2010) 18(2):453-7. doi:10.3233/ JAD-2009-1153

12. Johansson L, Guo X, Waern M, Östling S, Gustafson D, Bengtsson C, et al. Midlife psychological stress and risk of dementia: a 35-year longitudinal population study. Brain (2010) 133:2217-24. doi:10.1093/brain/awq116

13. Chi S, Yu JT, Tan MS, Tan L. Depression in Alzheimer's disease: epidemiology, mechanisms, and management. J Alzheimers Dis (2014) 42(3):739-55. doi:10.3233/JAD-140324

14. Letteneur L, Launer LJ, Andersen K, Dewey ME, Ott A, Copeland JRM, et al. Education and the risk for Alzheimer's disease: sex makes a difference. EURODEM pooled analyses. Am JEpidemiol (2000) 151(11):1064-71. doi:10.1093/oxfordjournals.aje.a010149 
15. Moser VA, Pike CJ. Obesity and sex interact in the regulation of Alzheimer's disease. Neurosci Biobehav Rev (2016) 67:102-16. doi:10.1016/j.neubiorev. 2015.08.021

16. Vest RS, Pike CJ. Gender, sex steroid hormones, and Alzheimer's disease. Horm Behav (2013) 63:2. doi:10.1016/j.yhbeh.2012.04.006

17. Melcangi RC, Giatti S, García-Segura LM. Levels and actions of neuroactive steroids in the nervous system under physiological and pathological conditions: sex-specific features. Neurosci Biobehav Rev (2016) 67:25-40. doi:10.1016/j.neubiorev.2015.09.023

18. Panzica G, Melcangi RC. Structural and molecular brain sexual differences: a tool to understand sex differences in health and disease. Neurosci Biobehav Rev (2016) 67:2-8. doi:10.1016/j.neubiorev.2016.04.017

19. Pike CJ, Carroll JC, Rosario ER, Barron A. Protective actions of sex steroid hormones in Alzheimer's disease. Front Neuroendocrinol (2009) 30(2):239-58. doi:10.1016/j.yfrne.2009.04.015

20. Fox M, Berzuini C, Knapp LA. Maternal breastfeeding history and Alzheimer's disease risk. J Alzheimers Dis (2013) 37(4):809-21. doi:10.3233/JAD-130152

21. Karim R, Dang H, Henderson VW, Hodis HN, John JS, Brinton RD, et al. Effect of reproductive history and exogenous hormone use on cognitive function in mid- and late life. J Am Geriatr Soc (2016) 64:12. doi:10.1111/jgs. 14658

22. Gatewood JD, Morgan MD, Eaton M, McNamara IM, Stevens LF, Macbeth AH, et al. Motherhood mitigates aging-related decrements in learning and memory and positively affects brain aging in the rat. Brain Res Bull (2005) 66(2):91-8. doi:10.1016/j.brainresbull.2005.03.016

23. Steinmetz D, Ramos E, Campbell SN, Morales T, Rissman RA. Reproductive stage and modulation of stress-induced tau phosphorylation in female rats. J Neuroendocrinol (2015) 27(11):827-34. doi:10.1111/jne.12323

24. Lindwall G, Cole RD. Phosphorylation affects the ability of tau protein to promote microtubule assembly. J Biol Chem (1984) 259(8):5301-5.

25. Johnson GV, Stoothof WH. Tau phosphorylation in neuronal cell function and dysfunction. J Cell Sci (2004) 117:5721-9. doi:10.1242/jcs.01558

26. Caceres A, Potrebic S, Kosik KS. The effect of tau antisense oligonucleotides on neurite formation of cultured cerebellar macroneurons. J Neurosci (1991) 11:1515-23.

27. Stoothof WH, Johnson GV. Tau phosphorylation: physiological and pathological consequences. Biochim Biophys Acta (2005) 1739(2-3):280-97. doi:10.1016/j.bbadis.2004.06.017

28. Martin L, Latypova X, Wilson CM, Magnaudeix A, Perrin ML, Yardin C, et al. Tau protein phosphatases in Alzheimer's disease: the leading role of PP2A. Ageing Res Rev (2013) 12:39-49. doi:10.1016/j.arr.2012.06.008

29. Tenreiro S, Eckermann K, Outeiro TF. Protein phosphorylation in neurodegeneration: friend or foe? Front Mol Neurosci (2014) 7:42. doi:10.3389/ fnmol.2014.00042

30. Liu F, Grundke-Iqbal I, Iqbal K, Gong C. Contributions of protein phosphatases PP1, PP2A, PP2B and PP5 to the regulation of tau phosphorylation. Eur J Neurosci (2005) 22:1942-50. doi:10.1111/j.1460-9568.2005.04391.x

31. Martin L, Latypova X, Wilson CM, Magnaudeix A, Perrin ML, Yardin C, et al. Tau protein kinases: involvement in Alzheimer's disease. Ageing Res Rev (2013) 12(1):289-309. doi:10.1016/j.arr.2012.06.003

32. Beurel E, Grieco SF, Jope RS. Glycogen synthase kinase-3 (GSK3): regulation, actions, and diseases. Pharmacol Ther (2015) 148:114-31. doi:10.1016/j. pharmthera.2014.11.016

33. Arendt T, Stieler J, Strijkstra AM, Hut RA, Rüdiger J, Van der Zee EA, et al. Reversible paired helical filament-like phosphorylation of tau is an adaptive process associated with neuronal plasticity in hibernating animals. J Neurosci (2003) 23(18):6972-81.

34. González-Arenas A, Piña-Medina AG, González-Flores O, Gómora-Arrati P, Carrillo-Martínez GE, Balandrán-Ruíz MA, et al. Expression pattern of Tau in the rat brain during pregnancy and the beginning of lactation. Brain Res Bull (2012) 89:3-4. doi:10.1016/j.brainresbull.2012.07.011

35. DeKosky ST, Scheff SW. Synapse loss in frontal cortex biopsies in Alzheimer's disease: correlation with cognitive severity. Ann Neurol (1990) 27(5):457-64. doi:10.1002/ana.410270502

36. Caramelli P, Robitaille Y, Laroche-Cholette A, Nitrini R, Gauvreau D, Joanette Y, et al. Structural correlates of cognitive deficits in a selected group of patients with Alzheimer's disease. Neuropsychiatry Neuropsychol Behav Neurol (1998) 11(4):184-90.

37. Giannakopoulos P, Herrmann F, Bussière T, Bouras C, Kövari E, Perl D, et al. Tangle and neuron numbers, but not amyloid load, predict cognitive status in Alzheimer's disease. Neurology (2003) 60:1495-500. doi:10.1212/01. WNL.0000063311.58879.01

38. Dai CL, Chen X, Kazim SF, Liu F, Gong CX, Grundke-Iqbal I, et al. Passive immunization targeting the $\mathrm{N}$-terminal projection domain of tau decreases tau pathology and improves cognition in a transgenic mouse model of Alzheimer disease and tauopathies. J Neural Transm (Vienna) (2015) 122:4. doi:10.1007/s00702-014-1315-y

39. Alzheimer Association. Alzheimer's disease facts and figures. Alzheimers Dement (2016) 12(4):459-509.

40. Snyder HM, Asthana S, Bain L, Brinton R, Craft S, Dubal DB, et al. Sex biology contributions to vulnerability to Alzheimer's disease: a think tank convened by the Women's Alzheimer's Research Initiative. Alzheimers Dement (2016) 12:11. doi:10.1016/j.jalz.2016.08.004

41. Grimm A, Mensah-Nyagan AG, Eckert A. Alzheimer, mitochondria and gender. Neurosci Biobehav Rev (2016) 67:89-101. doi:10.1016/j.neubiorev. 2016.04.012

42. Sotiropoulos I, Silva J, Kimura T, Rodrigues AJ, Costa P, Almeida OF, et al. Female hippocampus vulnerability to environmental stress, a precipitating factor in Tau aggregation pathology. J Alzheimers Dis (2015) 43:3. doi:10.3233/ JAD-140693

43. Devi L, Alldred MJ, Ginsberg SD, Ohno M. Sex-and brain region-specific acceleration of amyloidogenesis following behavioral stress in a mouse model of Alzheimer's disease. Mol Brain (2010) 3(34):1-11. doi:10.1186/1756-6606-3-34

44. Picazo O, Espinosa-Raya J, Briones-Aranda A, Cerbón M. Ovariectomy increases the age-induced hyperphosphorylation of Tau at hippocampal CA1. Cogn Process (2016) 17:4. doi:10.1007/s10339-016-0768-3

45. Barron AM, Pike CJ. Sex hormones, aging, and Alzheimer's disease. Front Biosci (2012) 4:976-97.

46. Guerra-Araiza C, Amorim MA, Camacho-Arroyo I, Garcia-Segura LM. Effects of progesterone and its reduced metabolites, dihydroprogesterone and tetrahydroprogesterone, on the expression and phosphorylation of glycogen synthase kinase- 3 and the microtubule-associated protein tau in the rat cerebellum. Dev Neurobiol (2007) 67(4):510-20. doi:10.1002/dneu.20383

47. Kinsley CH, Bardi M, Karelina K, Rima B, Christon L, Friedenberg J, et al. Motherhood induces and maintains behavioral and neural plasticity across the lifespan in the rat. Arch Sex Behav (2008) 37(1):43-56. doi:10.1007/ s10508-007-9277-x

48. Brunton P, Russell JA. The expectant brain: adapting for motherhood. Nat Rev Neurosci (2009) 9(1):11-25. doi:10.1038/nrn2280

49. Hansberg-Pastor V, González-Arenas A, Piña-Medina AG, Camacho-Arroyo I. Sex hormones regulate cytoskeletal proteins involved in brain plasticity. Front Psychiatry (2015) 6:165. doi:10.3389/fpsyt.2015.00165

50. González-Arenas A, Piña-Medina AG, González-Flores O, Galván-Rosas A, Gómora-Arrati P, Camacho-Arroyo I. Sex hormones and expression pattern of cytoskeletal proteins in the rat brain throughout pregnancy. J Steroid Biochem Mol Biol (2014) 139:154-8. doi:10.1016/j.jsbmb.2013.01.005

51. García-Segura LM, Balthazart J. Steroids and neuroprotection: new advances. Front Neuroendocrinol (2009) 30:v-ix. doi:10.1016/j.yfrne.2009.04.006

52. Azcoitia I, Arevalo MA, De Nicola AF, Garcia-Segura LM. Neuroprotective actions of estradiol revisited. Trends Endocrinol Metab (2011) 22:12. doi:10.1016/j.tem.2011.08.002

53. Goodenough S, Schleusner D, Pietrzik C, Skutella T, Behl C. Glycogen synthase kinase 3 beta links neuroprotection by 17beta-estradiol to key Alzheimer processes. Neuroscience (2005) 13(23):581-9. doi:10.1016/j.neuroscience. 2004.12.029

54. Cardona-Gomez P, Perez M, Avila J, Garcia-Segura LM, Wandosell F. Estradiol inhibits GSK3 and regulates interaction of estrogen receptors, GSK3, and beta-catenin in the hippocampus. Mol Cell Neurosci (2004) 25(3):363-73. doi:10.1016/j.mcn.2003.10.008

55. Shi HR, Zhu LQ, Wang SH, Liu XA, Tian Q, Zhang Q, et al. 17beta-estradiol attenuates glycogen synthase kinase-3beta activation and tau hyperphosphorylation in Akt-independent manner. J Neural Transm (Vienna) (2008) 115(6):879-88. doi:10.1007/s00702-008-0021-z

56. Alvarez-de-la-Rosa M, Silva I, Nilsen J, Pérez MM, Garcia-Segura LM, Avila J, et al. Estradiol prevents neural tau hyperphosphorylation characteristic of Alzheimer's disease. Ann N Y Acad Sci (2005) 1052:210-24. doi:10.1196/annals. 1347.016

57. Carroll JC, Rosario ER, Chang L, Stanczyc FZ, Oddo S, LaFerla FM, et al. Progesterone and estrogen regulate Alzheimer-like neuropathology in female 
3xTg-AD mice. J Neurosci (2007) 27(48):13357-65. doi:10.1523/JNEUROSCI. 2718-07.2007

58. Pinto-Almazán R, Calzada-Mendoza CC, Campos-Lara MG, Guerra-Araiza C. Effect of chronic administration of estradiol, progesterone, and tibolone on the expression and phosphorylation of glycogen synthase kinase- $3 \beta$ and the microtubule-associated protein tau in the hippocampus and cerebellum of female rat. J Neurosci Res (2012) 90:4. doi:10.1002/jnr.22808

59. Stein DG, Wright DW, Kellerman AL. Does progesterone have neuroprotective properties. Ann Emerg Med (2008) 51(2):164-72. doi:10.1016/j. annemergmed.2007.05.001

60. Singh M, Chang S. Progesterone and neuroprotection. Horm Behav (2013) 63:2. doi:10.1016/j.yhbeh.2012.06.003

61. Guerra-Araiza C, Amorim MA, Pinto-Almazán R, González-Arenas A, Campos MG, Garcia-Segura LM. Regulation of the phosphoinositide-3 kinase and mitogen-activated protein kinase signaling pathways by progesterone and its reduced metabolites in the rat brain. J Neurosci Res (2009) 87(2):470-81. doi:10.1002/jnr.21848

62. Amorim MA, Guerra-Araiza C, Pernia O, da Cruz e Silva EF, Garcia-Segura LM. Progesterone regulates the phosphorylation of protein phosphatases in the brain. J Neurosci Res (2010) 88:13. doi:10.1002/jnr.22442

63. Carroll JC, Rosario ER, Villamagna A, Pike CJ. Continuous and cyclic progesterone differentially interact with estradiol in the regulation of Alzheimer-like pathology in female $3 \times$ transgenic-Alzheimer's disease mice. Endocrinology (2010) 151:6. doi:10.1210/en.2009-1487

64. Neri-Gómez T, Espinosa-Raya J, Díaz-Cintra S, Segura-Uribe J, OrozcoSuárez S, Gallardo JM, et al. Tibolone modulates neuronal plasticity through regulating Tau, GSK3 $\beta / A k t / P I 3 K$ pathway and CDK5 p35/p25 complexes in the hippocampus of aged male mice. Neural Regen Res (2017) 12(4):588-95. doi:10.4103/1673-5374.205098

65. Irwin RW, Diaz-Brinton R. Allopregnanolone as regenerative therapeutic for Alzheimer's disease: translational development and clinical promise. Prog Neurobiol (2014) 113:40-55. doi:10.1016/j.pneurobio.2013.08.004

66. Pinto-Almazán R, Segura-Uribe JJ, Farfán-García ED, Guerra-Araiza C. Effects of tibolone on the central nervous system: clinical and experimental approaches. Biomed Res Int (2017) 2017:8630764. doi:10.1155/ 2017/8630764

67. Osborne LM, Gispen F, Sanyal A, Yenokyan G, Meilman S, Payne JL. Lower allopregnanolone during pregnancy predicts postpartum depression: an exploratory study. Psychoneuroendocrinology (2017) 79:116-21. doi:10.1016/j. psyneuen.2017.02.012

68. Grattan DR. Behavioural significance of prolactin signalling in the central nervous system during pregnancy and lactation. Reproduction (2002) 123(4):497-506. doi:10.1530/rep.0.1230497

69. Tejadilla D, Cerbón M, Morales T. Prolactin reduces the damaging effects of excitotoxicity in the dorsal hippocampus of the female rat independently of ovarian hormones. Neuroscience (2010) 169(3):1178-85. doi:10.1016/j. neuroscience.2010.05.074

70. Reyes-Mendoza J, Morales T. Post-treatment with prolactin protects hippocampal CA1 neurons of the ovariectomized female rat against kainic acidinduced neurodegeneration. Neuroscience (2016) 328:58-68. doi:10.1016/j. neuroscience.2016.04.030

71. Torner L, Neumann I. The brain prolactin system: involvement in stress response adaptations in lactation. Stress (2002) 5(4):249-57. doi:10.1080/ 1025389021000048638

72. Torner L. Actions of prolactin in the brain: from physiological adaptations to stress and neurogenesis to psychopathology. Front Endocrinol (2016) 7:25. doi:10.3389/fendo.2016.00025

73. Rissman RA, Lee K, Vale W, Sawchenko PE. Corticotropin-releasing factor receptors differentially regulate stress-induced tau phosphorylation. JNeurosci (2007) 27(24):6552-62. doi:10.1523/JNEUROSCI.5173-06.2007

74. Torner L, Karg S, Blume A, Kandasamy M, Kuhn HG, Winkler J, et al. Prolactin prevents chronic stress-induced decrease of adult hippocampal neurogenesis and promotes neuronal fate. J Neurosci (2009) 29(6):1826-33. doi:10.1523/ JNEUROSCI.3178-08.2009

75. Domínguez-Cáceres MA, García-Martínez JM, Calcabrini A, González L, Porque P, León J, et al. Prolactin induces c-Myc expression and cell survival through activation of Src/Akt pathway in lymphoid cells. Oncogene (2004) 23(44):7378-90. doi:10.1038/sj.onc.1208002

76. Plotnikov A, Li Y, Tran TH, Tang W, Palazzo JP, Rui H, et al. Oncogenemediated inhibition of glycogen synthase kinase 3 beta impairs degradation of prolactin receptor. Cancer Res (2008) 68(5):1354-61. doi:10.1158/0008-5472. CAN-07-6094

77. Dubal DB, Broestl L, Worden K. Sex and gonadal hormones in mouse models of Alzheimer's disease: what is relevant to the human condition? Biol Sex Differ (2012) 3(24):1-17. doi:10.1186/2042-6410-3-24

78. Uchoa MF, Moser VA, Pike CJ. Interactions between inflammation, sex steroids, and Alzheimer's disease risk factors. Front Neuroendocrinol (2016) 43:60-82. doi:10.1016/j.yfrne.2016.09.001

Conflict of Interest Statement: The authors declare that the research was conducted in the absence of any commercial or financial relationships that could be construed as a potential conflict of interest.

Copyright (c) 2018 Muñoz-Mayorga, Guerra-Araiza, Torner and Morales. This is an open-access article distributed under the terms of the Creative Commons Attribution License (CC BY). The use, distribution or reproduction in other forums is permitted, provided the original author(s) and the copyright owner are credited and that the original publication in this journal is cited, in accordance with accepted academic practice. No use, distribution or reproduction is permitted which does not comply with these terms. 